\title{
Collective bargaining as a two-level game: Direct learner-expert interactions
}

\author{
Martin S. Schilling \\ Matthew A. Mulford \\ London School of Economics \\ Ingmar R. Geiger \\ Technische Universität Berlin
}

\begin{abstract}
In this article, the authors introduce a new feature to model the collective bargaining process: a two-level game setting with direct learner-expert interaction. In the simulation ZUG UM ZUG 2015, participants form union and management negotiation teams to negotiate with each other (first level) and with a management or union "tariff commission," which has to approve proposed contracts (second level). To increase the degree of realism and the teaching effectiveness of the simulation, real-world negotiation experts negotiate in tariff commissions directly with participants. The authors also introduce a negotiation process to facilitate an efficient knowledge transfer from experts to learners.
\end{abstract}

KEYWORDS: collective bargaining; expert-student interaction; integrative setting; negotiation; simulation; two-level game

In most simulations, practitioners in the areas simulated are absent. Although simulation developers often interview professionals to create scenarios and computerbased evaluation systems, these experts are not included in the simulation settings. Learners interact with each other and/or with a computer, but a direct transfer of knowledge between practitioners in the field and the learners does not take place. With the simulation ZUG UM ZUG 2015 (Schilling, 2005), we followed a different path. Instead of having participants interact with a computer, we created a setting in which student teams negotiated both with each other and with professionals. We believe that this set-up leads to a more efficient transfer of knowledge. ZUG UM ZUG 2015 can therefore be classified as a behavioral collective bargaining simulation (Summers, 2004) with direct learner-expert interaction.

There is a long tradition of modeling collective bargaining negotiations. French (1961) was one of the first to create a labor-management negotiation environment in the laboratory. Following Walton and McKersie's (1965) seminal work on distributive and integrative approaches to collective bargaining, a series of other studies modeling labor-management interactions was published. These exercises can be divided roughly into three types: simulations and case studies (e.g., Bohret \& Wordelmann, 1974; Gahan \& Macdonald, 2001; Lavin, 1988; Sackman, 1974; Sandver \& Blaine, 1979; Stevens \& Bohlander, 1982), studies about teaching effectiveness and/or attitudinal 
change in collective bargaining settings (e.g., Axe, 1988; Brennenstuhl \& Blalack, 1978; Roderick, Wilterding, \& Eldredge, 1979; Sandver, 1983; Tracy \& Peterson, 1975), and participant-computer negotiations (e.g., Heintz \& Schreier, 1981; Murphy, Hines, \& Debenham, 1982; Stanton \& Greer, 1977). Simulation authors are often forced to make trade-offs between fidelity-the level of realism presented to the learner-and training effectiveness. Simulations model many of the important features of collective bargaining and simplify others. As an example of one common simplification, the "approval level" is eliminated in the laboratory negotiation. However, in many real-world collective bargaining situations, there are at least two levels to the negotiation. Negotiators must deal both with their direct opposites and with a body that has the power to approve or reject agreements.

Collective bargaining simulation developers often ignore these principal-agent relationships (e.g., Bohret \& Wordelmann, 1974; Heintz \& Schreier, 1981). Typically, a single union representative and a single management representative (or two negotiation teams) discuss a set of predefined issues. Although it is often the case that these simplifications of the real-world negotiation process are necessary, as high complexity can overwhelm novices (for a summary of relevant studies, see Feinstein \& Cannon, 2002), important elements of the labor relations process are missed. In the ZUG UM ZUG 2015 simulation described here, we add this two-level game feature that is otherwise often omitted. The participants in ZUG UM ZUG 2015 discuss possible contracts with real-world negotiation experts during the simulation. This direct learner-expert interaction at two levels of the negotiation process aims at enhancing both the fidelity and the training effectiveness of the simulation.

In the following sections, we introduce the scenario of ZUG UM ZUG 2015 and describe the integrative nature of the simulation, the two-level game feature, the negotiation process, and the learning objectives of ZUG UM ZUG 2015.

\section{Scenario}

The simulation is set in Germany in the year 2015. We use this future scenario to help the participating experts find common ground by getting away from their presentfocused, sector-specific experience. In addition to a description of the current (2015) situation, the participants receive a projection of the German railway sector's likely developments in 2016, including information about probable future growth in GNP, inflation, and predicted productivity increases in the railway industry. In addition, participants obtain details of the collective bargaining agreements concluded earlier in the year 2015 in related industries.

\section{Negotiation issues}

To make the issues and options as realistic as possible, the authors carried out extensive interviews with German railway experts from both management and labor. Based on those interviews, six negotiation issues were included in the simulation. Each issue 
TABLE 1: Actual Annual Labor Cost Increases in Percentages for Different Salary Increases and Contract Lengths

\begin{tabular}{lccccccc}
\hline & \multicolumn{7}{c}{ Contract Length (in months) } \\
\cline { 2 - 8 } Linear Increase in Salary & 12 & 14 & 16 & 18 & 20 & 22 & 24 \\
\hline $4.00 \%$ & $4.00 \%$ & $3.43 \%$ & $3.00 \%$ & $2.67 \%$ & $2.40 \%$ & $2.18 \%$ & $2.00 \%$ \\
$4.20 \%$ & $4.20 \%$ & $3.60 \%$ & $3.15 \%$ & $2.80 \%$ & $2.52 \%$ & $2.29 \%$ & $2.10 \%$ \\
$4.40 \%$ & $4.40 \%$ & $3.77 \%$ & $3.30 \%$ & $2.93 \%$ & $2.64 \%$ & $2.40 \%$ & $2.20 \%$ \\
$4.60 \%$ & $4.60 \%$ & $3.94 \%$ & $3.45 \%$ & $3.07 \%$ & $2.76 \%$ & $2.51 \%$ & $2.30 \%$ \\
$4.80 \%$ & $4.80 \%$ & $4.11 \%$ & $3.60 \%$ & $3.20 \%$ & $2.88 \%$ & $2.62 \%$ & $2.40 \%$ \\
$5.00 \%$ & $5.00 \%$ & $4.29 \%$ & $3.75 \%$ & $3.33 \%$ & $3.00 \%$ & $2.73 \%$ & $2.50 \%$ \\
$5.20 \%$ & $5.20 \%$ & $4.46 \%$ & $3.90 \%$ & $3.47 \%$ & $3.12 \%$ & $2.84 \%$ & $2.60 \%$ \\
$5.40 \%$ & $5.40 \%$ & $4.63 \%$ & $4.05 \%$ & $3.60 \%$ & $3.24 \%$ & $2.95 \%$ & $2.70 \%$ \\
$5.60 \%$ & $5.60 \%$ & $4.80 \%$ & $4.20 \%$ & $3.73 \%$ & $3.36 \%$ & $3.05 \%$ & $2.80 \%$ \\
$5.80 \%$ & $5.80 \%$ & $4.97 \%$ & $4.35 \%$ & $3.87 \%$ & $3.48 \%$ & $3.16 \%$ & $2.90 \%$ \\
$6.00 \%$ & N/A & N/A & N/A & N/A & N/A & N/A & N/A \\
\hline
\end{tabular}

includes several discrete options. For each option, the management team obtains information about the increase in labor costs (in percentages), whereas the union team obtains information about the relevant benefits of each option, measured in points.

Salary and contract length. Salary and contract length are almost always linked as a single, hybrid issue in collective bargaining in Germany. A standard contract length is 12 months. Management usually prefers to extend the contract beyond 12 months as a way to put off future demands for higher wages. For example, a 5\% rise in salary may be unacceptable to management in a 12-month contract but acceptable in a 24-month contract. To capture this dynamic, the actual annual cost of a percentage increase in salary (for management) is calculated as

$$
c=\frac{x * 12}{C L}
$$

where $c=$ cost, $C L=$ contract length, and $x=$ percentage increase in salary. Furthermore, we assume that above a certain threshold (in the simulation, this is set at greater than 6\%), the agreement is assumed to be infeasible. Indicative values are provided in Table 1.

Working time. Management and union parties have to negotiate changes in weekly working time. An alteration of the status quo is possible in both directions. Parties can agree on seven options, ranging from 37 to 40 hours per week. Changes in working time do not affect changes in salary.

Job security. The 2015 employees are particularly interested in job security. The parties can agree to institute a job security program in which management guarantees 
not to fire any staff (for nondisciplinary issues) for a discrete period of time. The parties can agree on no guarantee, a "political" statement, or a 1-, 2-, or 3-year guarantee.

Working break acknowledgment. Due to the nature of the railway industry, operational breaks in working days are common. Timetabling means that staff will often have breaks in their work. For example, a train driver may have to wait a short time for an incoming train. These breaks are particularly common during off-peak times and/or in areas with relatively low levels of service. Negotiation teams have to agree on how this break time will be integrated into total paid working time. Six options are available: operational breaks are not paid at all (best for employer side), $20 \%$ of the break time is paid, $40 \%$ of the break time is paid, $60 \%$ or $80 \%$ of the break time is paid, or operational breaks are fully paid (best for union side).

Vacation. The negotiation teams can agree on an increase or decrease in holidays. Seven discrete options are available, ranging from 23 to 29 days of annual vacation.

Ticket discounts for employees. Railway companies may offer employees and their relatives a variety of price reductions on network travel. Negotiation teams must decide on the number of free tickets per year. They can settle on five discrete options: 5 free national tickets per year per employee, 10 free national tickets per year per employee, 15 free national tickets per year per employee, unlimited travel on the national network for employees, or unlimited travel on the national network plus 10 free national tickets for relatives of employees.

\section{Reaching agreement}

To reach a final settlement, the parties must agree on one option for each of the six issues. The union calculates the overall benefits as the sum of the benefit points of each option agreed. The overall costs for management are determined by summing up the costs of each option agreed. We assume that the parties' choice of one option on one issue does not affect the valuation of options on other issues (preference independence).

Thresholds. To simulate the pressure of the rank and file of the union and the pressure of the companies' boards, both teams have to reach certain thresholds-reservation points - before they can agree to a deal (Raiffa, 1982; Raiffa, Richardson, \& Metcalfe, 2002; Thompson, 2005). At their reservation point, the parties are indifferent between settling the agreement and breaking off the negotiation. If a settlement is reached that results in more costs or less benefits than their reservation points, the team members are assumed to lose their jobs. If, for example, the management side agrees to a contract that results in a $7 \%$ increase in overall labor costs, and their reservation point is fixed at $6 \%$, the management side would have failed to negotiate a feasible contract. 
Strikes. In addition to normal negotiation tactics, the union teams can threaten and/or call strikes. In some real-world transport companies, it is easy for a union to mobilize its rank and file to close down a central station for at least 1 hour. However, there is always a certain risk of escalation. Specifically, members may strike for longer than the called-for time. After the 1st hour, there is a $40 \%$ chance that the strike will last another hour. If it lasts 2 hours, there is a $40 \%$ chance that it will last 3 , and so on. If the union calls a strike, they only know for sure that their members will strike for at least 1 hour. Each hour of strike is costly for management and the union, as the company is losing customers and the union has to pay their members.

Finally, and independent from the above-described short-term strikes, longer strikes are possible but only when one party announces the negotiation to be over without a settlement. This results in a major strike and ends the simulation.

\section{An integrative negotiation setting}

In distributive negotiations, the size of the surplus created by the overlap in reservation prices is fixed. Thus, one person's gain is necessarily another's loss. For example, a negotiation about the price of one piece of jewelry at an oriental bazaar is a distributive negotiation. Increasing the price by $x$ necessarily results in a gain of $x$ for the seller and a loss of $\mathrm{x}$ for the buyer. Collective bargaining negotiations, however, are rarely distributive in nature. Rather, they involve negotiations over multiple issues where negotiators' preferences across and within issues differ. These differences allow for trade-offs across issues that can increase the size of the negotiation surplus and, hence, the size of the payoffs to all parties. In the example of labor relations, assume the union is more concerned with guaranteed employment for a certain period than with a high rise in wages, whereas management is more concerned with a low pay rise, keeping labor costs at an acceptable level. In this case, a concession by the union away from its original demand of a high pay rise to a more moderate amount could be matched by guaranteed employment for a longer period by management, thus increasing the value of the agreement for both parties. Efficiency gains potentially occur in collective bargaining wherever such trade-offs across issues are possible. For descriptions of distributive versus integrative models, see Bazerman (2002), Bazerman and Neale (1992), Lewicki, Saunders, and Minton (2001), Raiffa (1982), Raiffa et al. (2002), Thompson (2005), and Walton and McKersie (1965).

With the six issues outlined above, ZUG UM ZUG 2015 is an integrative negotiation. Depending on the choices of options on each issue, the joint value of the final contract to both parties varies. Some contracts result in lower costs to the management side and more benefits to the unions than other agreements. The general idea is graphically displayed in Figure 1.

As illustrated in Figure 1, contract $A$ results in $c_{A}$ percentage increase in costs for the management and in $\mathrm{b}_{\mathrm{A}}$ benefit points for the unions. By agreeing to some mutually beneficial trades, as outlined above, the negotiators can move the contract position toward the efficiency border in the area northwest described by C, A, and B. 


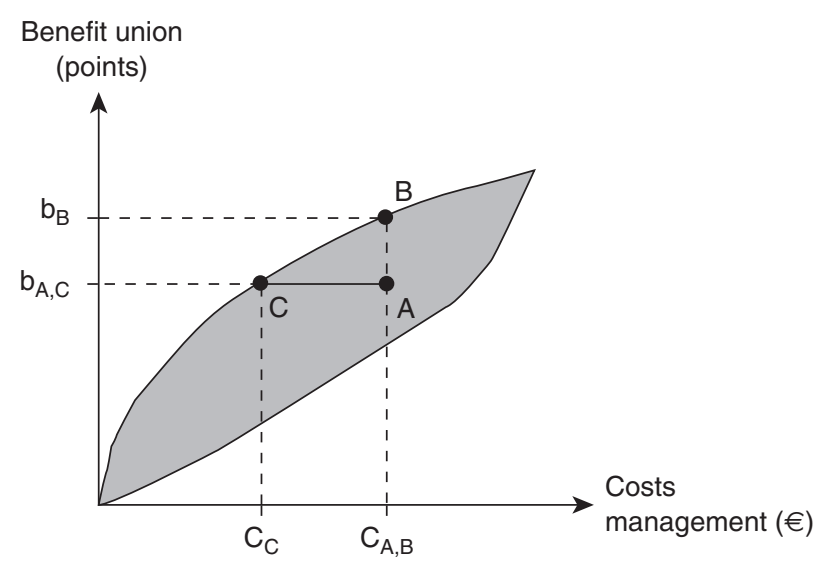

FIGURE 1: Contract Space for ZUG UM ZUG 2015

However, this does not mean that the negotiation is without conflict. Point B represents a contract where only the union profits from these trades from the initial point A. Contract B is - compared with contract A-equally costly for the management side $\left(c_{A}=c_{B}\right)$ but increases the benefit to the unions substantially $\left(b_{B}>b_{A}\right)$. Point $C$ represents the other extreme: The benefit to the unions is the same as for contract $A$ $\left(b_{A}=b_{C}\right)$. It is, however, substantially less costly for the management side $\left(c_{C}<c_{A}\right)$.

Participants of ZUG UM ZUG 2015 are therefore confronted with a mixedmotive situation (Thompson, 2005). On one hand, they have an interest in creating additional value in the settlement by agreeing on mutually beneficial trade-offs. On the other hand, each side wants to claim most of this value. Each party should, roledepending, aim either to maximize benefits or to minimize the increase in laborrelated costs. To find efficiency increasing trade-offs, confidential information has to be shared. If, however, one party reveals too much information, the other side can usually exploit this and claim more of the created surplus (Thompson, 1991).

\section{A two-level game}

The structure of a negotiation-independent of its distributive or integrative nature-significantly changes when negotiators must deal both with their direct opposites and with a person or body that has the power to approve or reject agreements (see Putnam, 1988). Participants in ZUG UM ZUG 2015 simulate a management or a union negotiation team of three fictional railway companies in Germany in the year 2015. These six teams negotiate with each other to attempt to reach an agreement on company-specific contracts (first level). However, these teams cannot autonomously determine the characteristics of the final contracts. Rather, each team 
must consult regularly during the negotiations with a management or a union "tariff commission" (second level). These commissions are made up of "real" management and union experts. To get contract proposals approved, the negotiation teams must have the consent of their respective commissions. This two-level structure is a common feature in collective bargaining negotiations in Germany.

\section{Expert participation}

In the first and second run of ZUG UM ZUG 2015, negotiation experts from six German unions (GDBA, GDL, IG BCE, IG Metall, transnet, ver.di) as well as from four German blue-chip companies (Die Bahn, Deutsche Bank, HOCHTIEF, Deutsche Lufthansa) and three employers' associations (AgV Banken, Arbeitgeberverband der Mobilitäts- und Verkehrsdiensleister, Gesamtmetall) simulated the tariff commissions. Within this two-level game setting, the experts interact directly with students, generating a rich, applied learning environment. In reality, three companies require three management and three union tariff commissions. Because it is difficult to recruit experts for six commissions, we formed one management and one union tariff commission. The negotiation teams of the three companies therefore negotiated with each other and consulted regularly with the single management or the union tariff commission. This two-level game setting of ZUG UM ZUG 2015 is displayed in Figure 2.

\section{Simulation development and runs}

Between 2003 and 2005, we ran 10 alpha tests with codevelopers to calibrate the point-scores of the to-be-negotiated issues and 2 beta tests with student groups to test the two-level game structure. In April 2004 and November 2005, we organized the first two simulation runs with scholarship holders from the Foundation of the German Business and the union-led Hans-Böckler Foundation as members of the first-level negotiation teams. According to their feedback, the processes, as outlined below, proved to be highly valuable in teaching negotiation tactics firsthand. Participating experts confirmed the simulation's external validity on the major issues of collective bargaining in the railway industry. In their eyes, particularly the pressure emanating from a tight schedule, ambitious demands by the tariff commissions, and the high emotional involvement of real-world collective bargaining were reproduced well by the ZUG UM ZUG 2015 simulation. Due to the number of negotiation rounds, strategy evolution over time was a major lesson that the experts were able to pass on to the students. As one management representative put it, "You could feel the participants' rising learning curves across the different phases of the simulation."

\section{Simulation process}

To facilitate this two-level game setting in a 1-day simulation, we developed a system that enabled all participants to negotiate with a minimum of pauses. After a 


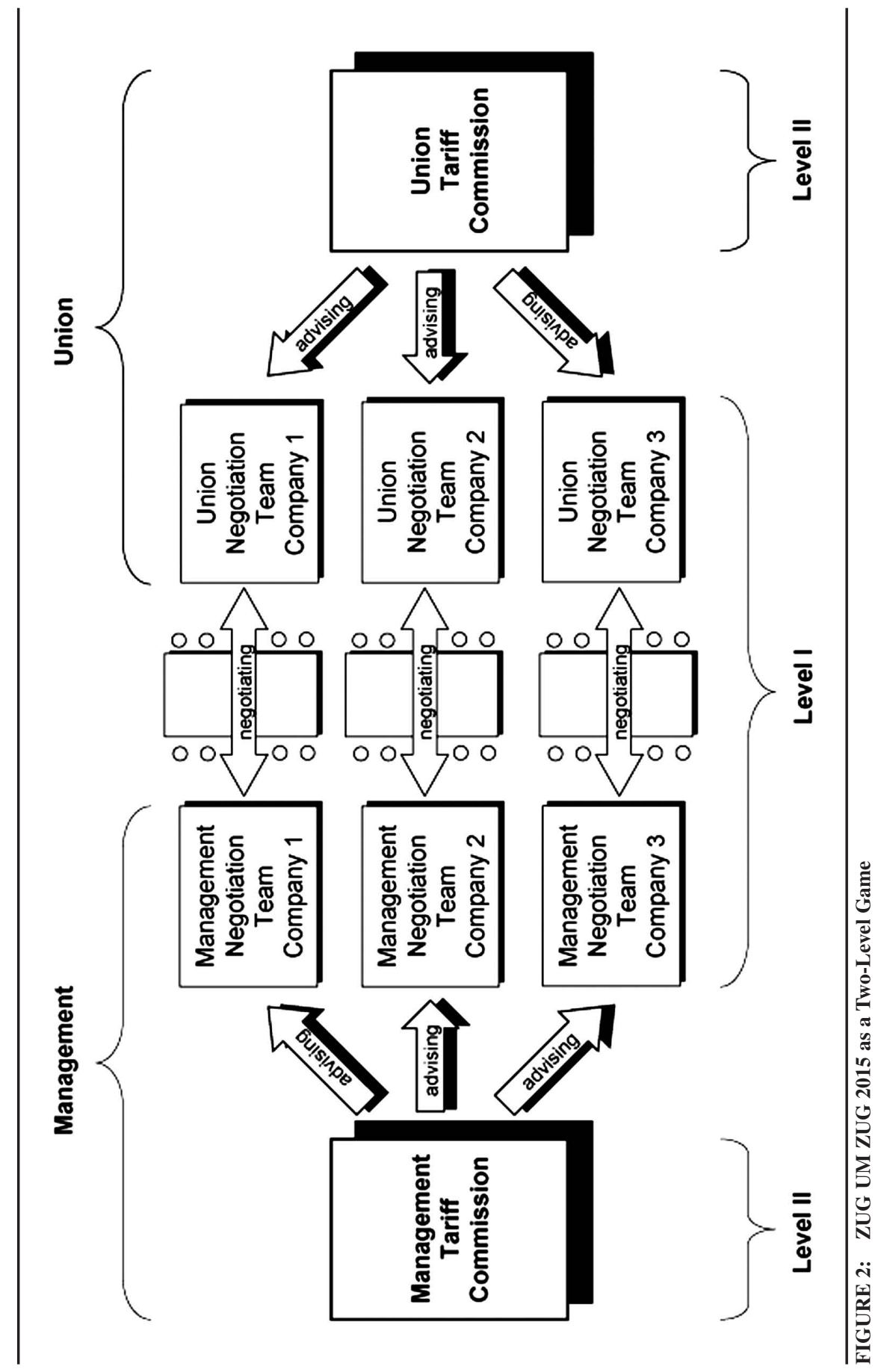


half-hour introduction to the processes and issues of ZUG UM ZUG 2015, each negotiation team and the tariff commission consulted in private to develop a negotiation strategy. This strategy meeting was followed by four 1-hour-long negotiation rounds. In each of these rounds, the teams consulted for 20 minutes with the tariff commission and negotiated for 40 minutes with their company's other negotiation team. Each company had, in each round, a fixed time slot in which they consulted with their respective tariff commission. The teams negotiating the contract for Company 1 consulted with their commissions in the first 20 minutes of the round and negotiated with each other in the last 40 minutes. The negotiating parties of Company 2 negotiated for the first 20 minutes of the round with each other, consulted subsequently for 20 minutes with their tariff commissions, and negotiated on the first level in the last $20 \mathrm{~min}$ utes of the round. The representatives of Company 3 negotiated for the first 40 minutes with each other and consulted in the last 20 minutes with the tariff commissions. With this system, the experts on the second level were able to transfer knowledge to the students during the whole round. In the last negotiation round, one representative of the tariff commission accompanied the negotiation teams to the first-level negotiations to enable the teams to sign a contract directly.

After the parties signed the final contracts, the tariff commissions gave feedback to the negotiation teams about their bargaining tactics. In addition, the results were analyzed with a computer-based model as shown generally in Figure 1. The analyses describe the efficiency of the agreed-on compromises and potential ways to improve the value of the agreement to both sides. This process also allowed the negotiation teams' results to be compared with each other, thus identifying teams who yielded a higher surplus than others. The complete negotiation process, leading to these results, is displayed in Figure 3.

\section{Learning objectives}

ZUG UM ZUG 2015 has been primarily developed for a sequence of joint seminars for the Foundation of the German Business and the union-led Hans-Böckler Foundation in Germany. It was designed to serve a number of goals.

\section{Build trust between future management and union leaders}

ZUG UM ZUG 2015 has location-specific objectives as it is used to build interpersonal trust between young management and union representatives in Germany. With ZUG UM ZUG 2015, we aim to foster a more cooperative atmosphere in future collective bargaining situations in Germany. We ask students from the union's foundation (Hans-Böckler) and the management-oriented Foundation of the German Business to form joint negotiation teams. Thus, potential real-life "opponents" will be team "partners" in a laboratory situation and share the experience of working toward a common goal. According to participants' feedback from the first two pilot studies, mixed-team structures proved to be a major source of mutual trust building. 


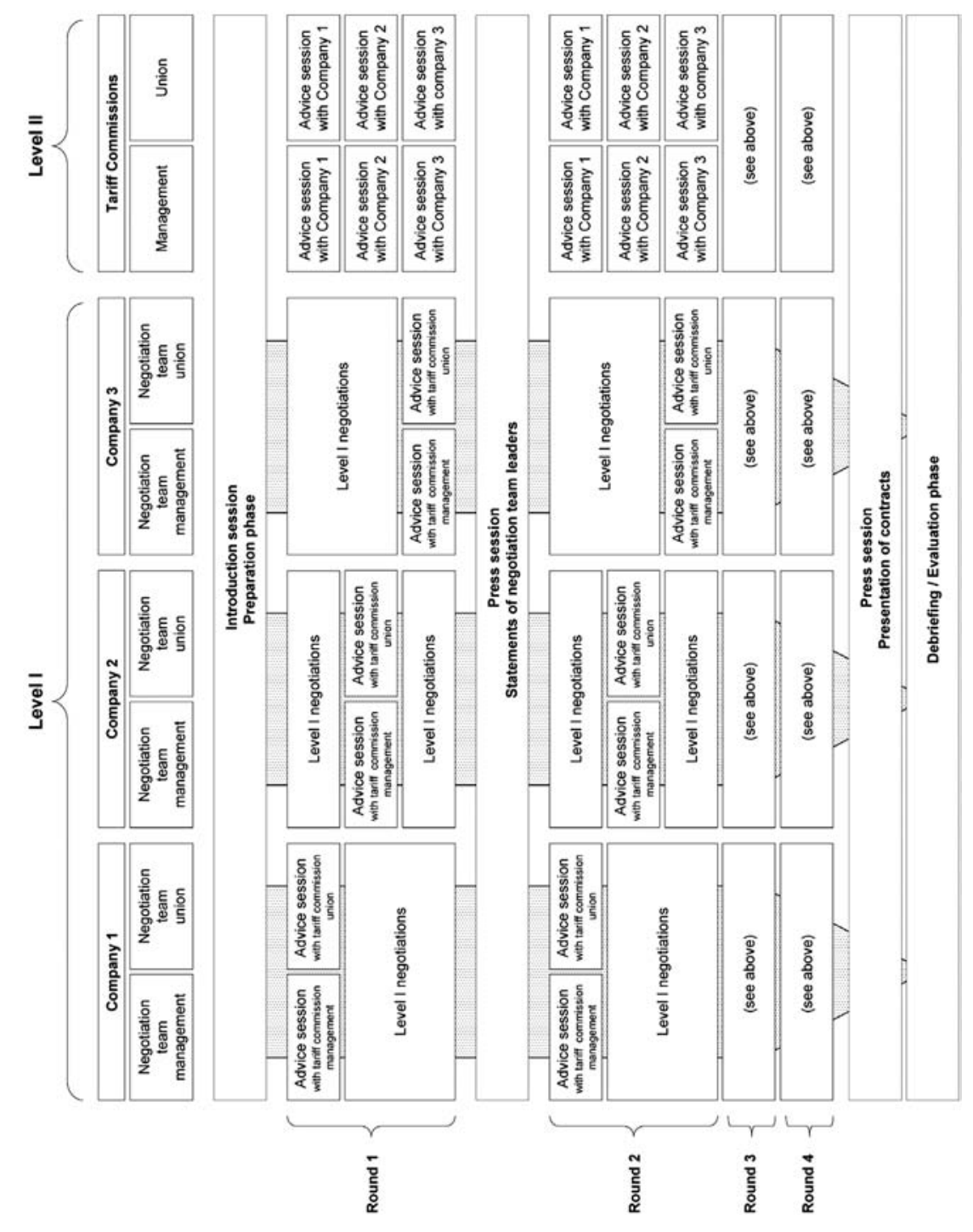

טُ 


\section{Increase negotiators' abilities to construct efficient and advantageous contracts}

ZUG UM ZUG 2015 provides negotiation teams with a complex setting to apply efficiency-increasing bargaining tactics. Increased efficiency in this context refers to negotiated changes that lead to an increase in value for at least one of the teams, without a decrease in value to the other team. In addition to jointly seeking increases in agreement efficiency, participants need to either minimize increases in labor costs (management) or maximize benefits to the employees (unions). As increases in benefits usually lead to some increases in costs, participants must deal with conflicting objectives: They have to increase the size of the to-be-negotiated pie, while securing the biggest slice of it for themselves. In other words, participants experience the mixed-motive environment of integrative negotiation (Thompson, 2005).

\section{Create insights into some of the unique issues of collective bargaining}

Participants of ZUG UM ZUG 2015 obtain firsthand insights into negotiation tactics and communication styles of management and labor by interacting directly with real-world collective bargaining experts. For union teams, this means gaining experience in the use (and abuse) of issuing strike threats. The democratic, discussionoriented style of many unions is simulated as well. Management teams obtain knowledge on when and how to make offers to the unions and get a better insight into the more hierarchical decision structures typical of management.

\section{Conclusion}

ZUG UM ZUG 2015 is a collective bargaining simulation with a two-level game feature with direct learner-expert interaction. We added these features to a more traditional integrative negotiation simulation to increase educational validity. To make a simulation like this feasible, the negotiation situation has to be radically simplified. The number of issues is limited, options in each issue are clearly defined, and preferences are quantified. As the setting was complicated to develop, we have focused-until now-more on verification than on validation (as discussed in Feinstein \& Cannon, 2002).

The simulation continues to undergo improvements and refinements. First, the quantitative preferences of the union and management sides will be continually reassessed based on comments from negotiation experts in the German railway industry. Second, several industry-specific alterations of the ZUG UM ZUG template are planned to develop training opportunities for young union and management negotiators. Third, the trust-building objectives will be strengthened not only by mixing negotiation teams with scholarship holders of a management and a union-led foundation but also by exchanging experts in the tariff commission.

We view the two-level game structure with direct learner-expert interactions as one way to efficiently facilitate knowledge transfers from experts to learners. This system 
might be useful in other simulation contexts as well. Total enterprise simulations, for example, could possibly be organized with real-world experts on a second level. The experts could consult with different groups of students on how to develop company strategies. Although we think that such an approach is promising, the applicability of this idea to domains other than negotiation simulations is still to be proven.

\section{References}

Axe, B. S. (1988). Should students play games in labor relations? Developments in Business Simulation \& Experiential Exercises, 15, 165-169.

Bazerman, M. H. (2002). Judgment in managerial decision making (5th ed.). New York: John Wiley \& Sons.

Bazerman, M. H., \& Neale, M. A. (1992). Negotiating rationally. New York: Free Press.

Bohret, C., \& Wordelmann, P. (1974). ARKOSI, ODIPOS, AND GAPSI-Experiences with three simulation games in the Federal Republic of Germany. Simulation \& Gaming, 5(2), 186-200.

Brennenstuhl, D. C., \& Blalack, R. O. (1978). Role preference and vested interest in a bargaining environment. Simulation \& Games, 9(1), 53-65.

Feinstein, A. H., \& Cannon, H. M. (2002). Constructs of simulation evaluation. Simulation \& Gaming, 33(4), 425-440.

French, W. (1961). A collective bargaining game. Journal of the American Society of Training Directors, $15,10-13$.

Gahan, P. G., \& Macdonald, R. D. (2001). Collective bargaining simulation: The Federal Football League versus the National Association of Professional Footballers. Sport Management Review, 4, 89-114.

Heintz, T., \& Schreier, J. W. (1981). A structured approach to the simulation of labor negotiation. Journal of Experiential Learning and Simulation, 3(4), 248-259.

Lavin, M. T. (1988). Collective bargaining in the city of Elson: A public sector experience. Developments in Business Simulation \& Experiential Exercises, 15, 161-164.

Lewicki, R. J., Saunders, D. M., \& Minton, J. W. (2001). Essentials of negotiation (2nd ed.). New York: McGraw-Hill.

Murphy, M. J., Hines, S. C., \& Debenham, J. D. (1982). Simulating collective bargaining in education. Simulation \& Gaming, 13(2), 131-144.

Putnam, R. (1988). Diplomacy and domestic politics: The logic of two-level games. International Organization, 42, 427-460.

Raiffa, H. (1982). The art and science of negotiation. Cambridge: Harvard University Press.

Raiffa, H., Richardson, R., \& Metcalfe, D. (2002). Negotiation analysis-The science and art of collaborative decision making. Cambridge: Belknap Press.

Roderick, R. D., Wilterding, J. A., \& Eldredge, D. (1979). Simulation as a technique for teaching collective bargaining. Insights into Experimental Pedagogy, 6, 56-59.

Sackman, M. (1974). A collective bargaining negotiation simulation: Settle or strike. Simulation, Games and Experimental Learning Techniques, 1, 70-76.

Sandver, M. H. (1983). Attitudes of union and management representatives. Simulation \& Gaming, 14(4), 381-390.

Sandver, M. H., \& Blaine, H. R. (1979). The process of writing a collective bargaining simulation: A case study in practical pedagogy. Insights into Experimental Pedagogy, 6, 49-52.

Schilling, M. S. (2005). ZUG UM ZUG 2015. Berlin: CDNA. (Available from Martin S. Schilling, Köpenicker Straße 159, 10997 Berlin, Germany)

Stanton, W. W., \& Greer, C. R. (1977). An interactive simulation of private sector collective bargaining. New Horizons in Simulation Games and Experimental Learning, 4, 32-39.

Stevens, G. E., \& Bohlander, G. W. (1982). Labor management negotiations-Practice for tomorrow. Simulation \& Gaming, 13(4), 468-483.

Summers, G. J. (2004). Today's business simulation industry. Simulation \& Gaming, 35(2), 208-241. 
Thompson, L. (1991). Information exchange in negotiation. Journal of Experimental Social Psychology, 27(2), 161-179.

Thompson, L. (2005). The mind and the heart of the negotiator (3rd ed.). Upper Saddle River, NJ: Prentice Hall.

Tracy, L., \& Peterson, R. B. (1975). Classroom collective bargaining simulation: How close to the real thing? Relations Industrielles, 30(1), 98-111.

Walton, R., \& McKersie, R. (1965). A behavioral theory of labor relations. New York: McGraw-Hill.

Martin S. Schilling holds an MSc in decision science from the London School of Economics and a master's degree in psychology from the Free University of Berlin. He is developing, in his doctoral research at the London School of Economics, methodologies to aid groups of negotiators and decision makers to make better decisions. He is the president of the Centre for Decision and Negotiation Analysis in Germany. The Centre regularly organizes negotiation simulations and workshops in cooperation with experts from both unions and management.

Matthew A. Mulford holds a PhD and MSc from the University of Oregon and a master's degree from New York University. He is a senior lecturer in negotiation analysis and quantitative methodology at the London School of Economics. He is also the director of Academic Affairs for the TRIUM Global EMBA program. His research interests include behavioral decision making, negotiation theory, and experimental game theory.

Ingmar R. Geiger holds a master's degree in industrial engineering and management from Technische Universität Berlin and a master's in business from ESCP-EAP European School of Management Paris. Currently, he is a PhD student and a research associate at Technische Universität Berlin. In his research, he is mainly focused on marketing negotiations. He is the vice president of the Centre for Decision and Negotiation Analysis in Germany.

ADDRESSES: MSS: Operations Research Department, London School of Economics, Houghton Street, London, WC2A 2AE,UK; e-mail: m.schilling@lse.ac.uk; www.cdna-online.org. MAM: TRIUM Global EMBA, London School of Economics, Houghton Street, London, WC2A 2AE, UK; telephone: +44-20-7955-6834; e-mail: m.mulford@lse.ac.uk.IRG: Technische Universität Berlin, Bereich Strategisches Management, Sekretariat H90, Straße des 17. Juni 135, 10623 Berlin, Germany; telephone: +49-30-3142-6720; e-mail:geiger@strategie .tu-berlin.de. 